\title{
Use of near-surface channel conductance and differential capacitance versus potential measurements to correlate inversion layer formation with low effective surface recombination velocities at $\boldsymbol{n}$-Si/liquid contacts
}

\author{
David J. Michalak and Nathan S. Lewis ${ }^{\text {a) }}$ \\ Division of Chemistry and Chemical Engineering, 127-72 California Institute of Technology, Pasadena, \\ California 91125
}

(Received 20 December 2001; accepted for publication 20 March 2002)

\begin{abstract}
Near-surface channel conductance measurements, differential capacitance versus potential measurements, and surface recombination velocity measurements have been performed on (111)and (100)-oriented $n$-type Si samples in contact with nitrogen and/or liquid electrolyte solutions containing $\mathrm{I}_{2}, \mathrm{I}_{2} / \mathrm{I}^{-}$, ferrocene ${ }^{+/ 0}$, or decamethylferrocene ${ }^{+/ 0}$ in either methanol or tetrahydrofuran. $\mathrm{Si} /$ liquid contacts that displayed a low effective surface recombination velocity $S$ corresponded to those that formed an inversion layer at the solid/liquid contact as indicated by channel conductance measurements or by differential capacitance versus potential measurements. Contacts that did not produce an inversion layer at the Si surface did not produce low effective $S$ values. The observed behavior is consistent with the known energetics of Si/liquid contacts and provides an explanation for the low effective $S$ values observed in these systems. (C) 2002 American Institute of Physics. [DOI: $10.1063 / 1.1479456]$
\end{abstract}

We have previously demonstrated that immersion of H-terminated (111)-oriented Si surfaces into alcoholic solutions that contain mild oxidants, including ferrocenium $\left(\mathrm{Fc}^{+}\right), \mathrm{I}_{2}$, and $\mathrm{Br}_{2}$, produces a common surface chemistry involving formation of surficial $\mathrm{Si}$ alkoxyl ( $\mathrm{Si}-\mathrm{OR}$ ) groups. ${ }^{1,2}$ The effective surface recombination velocity $S$ of all of these Si/liquid interfaces is $<1 \times 10^{2} \mathrm{~cm} \mathrm{~s}^{-1}$. $^{3-7}$ The effective surface recombination velocity of $\mathrm{Si}$ in contact with tetrahydrofuran (THF) solutions containing either $\mathrm{I}_{2}$ or $\mathrm{Fc}^{+/ 0}$ is also quite low, ${ }^{3-6}$ even though these electrolytes do not produce surficial Si-alkoxide groups. ${ }^{1,2}$ This behavior was previously ascribed to the formation of an inversion layer at the $n$-type Si surface, which produces low effective surface recombination velocities for a wide range of actual carrier trap densities at the $n$-Si/liquid interface. ${ }^{3,4}$ This hypothesis was supported by the rapid, reversible increase in $S$ that was observed when these surfaces were removed from contact with the electrolytes and measured in inert $\mathrm{N}_{2(g)}$ ambients, and by the observation of high $S$ values when such surfaces were placed in contact with electrolytes that were not expected to produce a high charge carrier concentration at the Si/liquid contact. ${ }^{3,4}$ In this work, we report the results of near-surface channel conductance measurements and differential capacitance versus potential measurements that directly confirm the formation of an inversion layer when $n$-type $\mathrm{Si}$ is placed in contact with these electrolyte solutions. These measurements also show that the disappearance of the inversion layer is reversible when these surfaces are put in contact with other types of ambients. Finally, the formation of an inversion layer is well-correlated with an observed low effective $S$ value for these systems.

Using conventional Si device fabrication processes, two

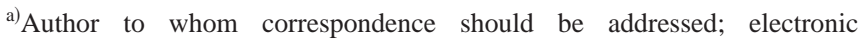
mail: nslewis@its.caltech.edu
}

regions of $p^{+}$-Si (each $0.25 \mathrm{~cm} \times 0.84 \mathrm{~cm}$ separated by 0.1 $\mathrm{cm}$ along the long axis) were formed in $40 \Omega \mathrm{cm}$ resistivity, (100)-oriented, 525- $\mu$ m-thick $n$-type $\mathrm{Si}$ substrates. Ohmic contacts of $\mathrm{Al}$ were then formed on top of the $p^{+}-\mathrm{Si}$ regions, producing a structure that allowed measurement of the conductance in the near-surface channel between the two $p^{+}-\mathrm{Si}$ regions. Details of the fabrication process have been described previously. ${ }^{8}$ A significant dark dc conductance between the implanted $p^{+}-\mathrm{Si}$ regions can only be observed when an inversion layer has been formed in the near-surface region of the $n$-type $\mathrm{Si}$ sample. Otherwise, high-impedance rectifying behavior should be observed for the blocking $p^{+}-n-p^{+}$current path.

To insure the uninterrupted formation of any inversion layer in the $n$-Si sample, the full area of the $n$-Si surface between the two $p^{+}$regions, along with a small portion of the $p^{+}$-Si regions, was exposed to the ambients of interest. Contact of redox-active electrolytes to portions of the exposed $p^{+}$-Si regions and to their Ohmic contacts will produce a component of the measured conductance that arises from Faradaic current flow through the electrolyte solution. ${ }^{8}$ This undesirable but unavoidable component of the signal is minimized by using relatively low concentrations of redox species, and can be readily separated from the component that corresponds to the current path through the solid by analyzing the impedance data as a function of frequency. ${ }^{8}$

Figure 1 displays the impedance versus frequency data for a $\mathrm{Si}$ channel structure in contact with $\mathrm{N}_{2(g)}$, $\mathrm{CH}_{3} \mathrm{OH}-0.1 \mathrm{M} \quad \mathrm{LiClO}_{4}, \quad \mathrm{CH}_{3} \mathrm{OH}-0.1 \mathrm{M} \quad \mathrm{LiClO}_{4}-0.5$ $\mathrm{mM}$ decamethylferrocene $\left(\mathrm{Me}_{10} \mathrm{Fc}\right)-0.5 \mathrm{mM} \quad \mathrm{Me}_{10} \mathrm{Fc}^{+}$, $\mathrm{CH}_{3} \mathrm{OH}-0.1 \mathrm{M} \mathrm{LiClO}_{4}-0.5 \mathrm{mM} \mathrm{I}$, and $\mathrm{CH}_{3} \mathrm{OH}-0.1 \mathrm{M}$ $\mathrm{LiClO}_{4}-0.5 \mathrm{mM} \mathrm{Fc}-0.5 \mathrm{mM} \mathrm{Fc}^{+}$, respectively. The $\mathrm{Si} / \mathrm{CH}_{3} \mathrm{OH}-\mathrm{Fc}^{+/ 0}$ and $\mathrm{Si} / \mathrm{CH}_{3} \mathrm{OH}-\mathrm{Me}_{10} \mathrm{Fc}^{+/ 0}$ data are in accord with prior work ${ }^{8}$ and demonstrate that the measured channel impedance is much lower, and has a significantly 


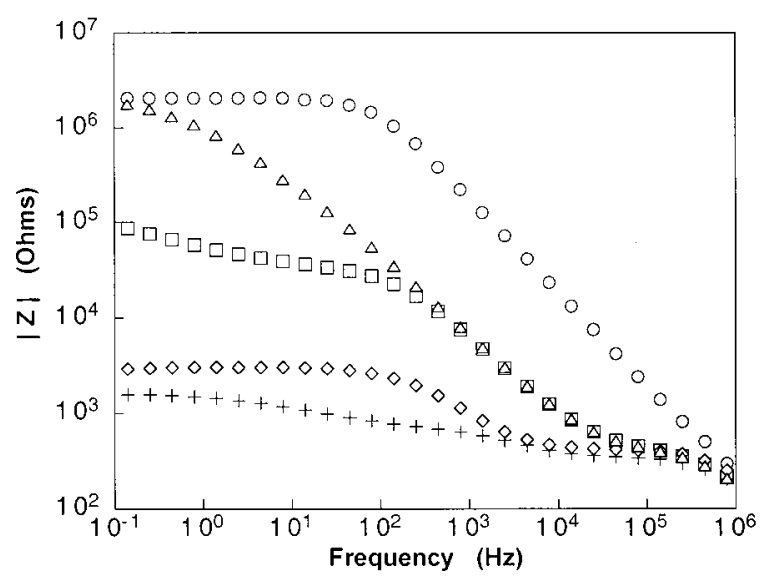

FIG. 1. Impedance vs frequency data for a $\mathrm{Si}$ channel structure in contact with $N_{2(g)}$ (circles), $\mathrm{CH}_{3} \mathrm{OH}-0.1 \mathrm{M} \mathrm{LiClO}_{4}$ (triangles), $\mathrm{CH}_{3} \mathrm{OH}-0.1 \mathrm{M}$ $\mathrm{LiClO}_{4}-0.5 \mathrm{mM} \quad \mathrm{Me}_{10} \mathrm{Fc}-0.5 \mathrm{mM} \quad \mathrm{Me}_{10} \mathrm{Fc}^{+}$(squares), $\mathrm{CH}_{3} \mathrm{OH}-0.1 \mathrm{M}$ $\mathrm{LiClO}_{4}-0.5 \mathrm{mM} \mathrm{I}_{2}$ (diamonds), and $\mathrm{CH}_{3} \mathrm{OH}-0.1 \mathrm{M} \mathrm{LiClO}_{4}-0.5 \mathrm{mM} \mathrm{Fc}-$ $0.5 \mathrm{mM} \mathrm{Fc}^{+}$(crosses).

different dependence on frequency, when the $n$-type $\mathrm{Si}$ is in contact with the $\mathrm{CH}_{3} \mathrm{OH}-0.1 \mathrm{M} \mathrm{LiClO}_{4}-\mathrm{Fc}^{+/ 0}$ redox system than when it is in contact with either $\mathrm{N}_{2(g)}$ or $\mathrm{CH}_{3} \mathrm{OH}-0.1 \mathrm{M} \mathrm{LiClO}_{4}$. Analysis of these data to extract the low-frequency channel conductance yields an equilibrium barrier height of $\approx 1.0 \mathrm{~V}$ for the $n-\mathrm{Si} / \mathrm{CH}_{3} \mathrm{OH}-\mathrm{Fc}^{+/ 0}$ contact $^{8}$ and provides direct evidence for formation of an inversion layer at this solid/liquid contact. However, the redox potential of the $\mathrm{CH}_{3} \mathrm{OH}-\mathrm{Me}_{10} \mathrm{Fc}^{+/ 0}$ solution is not positive enough to produce an inversion layer on $n$-type $\mathrm{Si}^{9},{ }^{9}{ }^{10}$ so the impedance spectrum of this contact primarily represents the residual Faradaic conductance between the $p^{+}$regions facilitated by interfacial charge carrier exchange with the redoxactive electrolyte solution. Similar to the case of $\mathrm{CH}_{3} \mathrm{OH}-0.1 \mathrm{M} \mathrm{LiClO}_{4}-0.5 \mathrm{mM} \mathrm{Fc}^{+/ 0}$, the low-frequency channel conductance increased substantially when the sample was in contact with the $\mathrm{CH}_{3} \mathrm{OH}-0.1 \mathrm{M}$ $\mathrm{LiClO}_{4}-0.5 \mathrm{mM} \mathrm{I}_{2}$ solution, but not when the sample was in contact with either $\mathrm{N}_{2(g)}$ or $\mathrm{CH}_{3} \mathrm{OH}-0.1 \mathrm{M} \mathrm{LiClO}_{4}$.

Table I summarizes the analysis of the impedance data

TABLE I. Near-surface channel conductance measurements and surface recombination velocity measurements for $\mathrm{Si}$ in contact with various ambients.

\begin{tabular}{lcc}
\hline \hline & $\left|Z_{o}\right|^{\mathrm{a}}(\Omega)$ & $S\left(\mathrm{~cm} \mathrm{~s}^{-1}\right)$ \\
\hline$N_{2(g)}$ & $(2.7 \pm 0.9) \times 10^{6}$ & $1160 \pm 190$ \\
$\mathrm{CH}_{3} \mathrm{OH}-0.1 \mathrm{M} \mathrm{LiClO}_{4}$ & $(2.4 \pm 0.2) \times 10^{6}$ & $1110 \pm 110$ \\
$\mathrm{CH}_{3} \mathrm{OH}-0.1 \mathrm{M} \mathrm{LiClO}_{4}-0.5 \mathrm{mM}$ & $(1.5 \pm 0.1) \times 10^{5} \mathrm{~b}$ & $1765 \pm 95$ \\
$\mathrm{Me}_{10} \mathrm{Fc}-0.5 \mathrm{mM} \mathrm{Me}{ }_{10} \mathrm{Fc}^{+}$ & & \\
$\mathrm{CH}_{3} \mathrm{OH}-0.1 \mathrm{M} \mathrm{LiClO}_{4}-0.5 \mathrm{mMI}_{2}$ & $(2.9 \pm 0.1) \times 10^{3}$ & $63 \pm 20$ \\
$\mathrm{CH}_{3} \mathrm{OH}-0.1 \mathrm{M} \mathrm{LiClO}_{4}-0.5 \mathrm{mM}$ & $(1.5 \pm 0.1) \times 10^{3}$ & $38 \pm 7$ \\
$\mathrm{Fc}-0.5 \mathrm{mM} \mathrm{Fc}$ & & \\
\hline \hline
\end{tabular}

${ }^{a}$ Magnitude of the channel impedance as the measurement frequency, $f$, goes to zero. Standard deviations of $Z_{o}$ and $S$ represent variations in the mean values for at least three independent trials of each type of Si contact.

${ }^{b}$ The channel impedance data for $\mathrm{Me}_{10} \mathrm{Fc}^{+/ 0}$ is evaluated at $0.01 \mathrm{~Hz}$ and does not represent a true extrapolation to $f=0$. A major contribution of this impedance is due to Faradaic charge transfer into the solution as indicated by a nonzero phase angle and a frequency-dependent impedance.
TABLE II. Barrier heights and surface recombination velocities for various Si/liquid contacts.

\begin{tabular}{|c|c|c|}
\hline & $\begin{array}{l}\text { Barrier height } \\
\text { (V) }\end{array}$ & $\begin{array}{c}S \\
\left(\mathrm{~cm} \mathrm{~s}^{-1}\right)^{\mathrm{a}}\end{array}$ \\
\hline $\begin{array}{l}\mathrm{CH}_{3} \mathrm{OH}-1.0 \mathrm{M} \mathrm{LiClO}_{4}-0.05 \mathrm{M} \\
\mathrm{Fc}-0.05 \mathrm{M} \mathrm{Fc}^{+}\end{array}$ & $0.95 \pm 0.03$ & $16 \pm 1$ \\
\hline $\begin{array}{l}\mathrm{CH}_{3} \mathrm{OH}-1.0 \mathrm{M} \mathrm{LiClO}_{4}-0.05 \mathrm{M} \\
\mathrm{I}-0.05 \mathrm{M} \mathrm{I}_{2}\end{array}$ & $0.83 \pm 0.05$ & $14 \pm 4$ \\
\hline $\begin{array}{l}\text { THF-1.0 M LiClO } \\
4-0.05 \mathrm{M} \\
\mathrm{Fc}^{-}-0.005 \mathrm{M} \mathrm{Fc}^{+}\end{array}$ & $1.04 \pm 0.03$ & $50 \pm 30$ \\
\hline $\begin{array}{l}\mathrm{THF}-1.0 \mathrm{M} \mathrm{LiClO}_{4}-0.05 \mathrm{M} \\
\mathrm{I}^{-}-0.05 \mathrm{M} \mathrm{I}_{2}\end{array}$ & $0.93 \pm 0.09$ & $30 \pm 10$ \\
\hline
\end{tabular}

${ }^{\mathrm{a}}$ From Ref. 3.

and also presents $S$ values measured for these same $\mathrm{Si} /$ ambient contacts using photoconductivity decay methods 3,4 on long lifetime, float-zone, double-side polished, (111)oriented $n$-Si samples. The Si/liquid contacts that showed a low effective $S$ value as probed by photoconductivity decay measurements also formed an inversion layer in contact with the electrolyte solutions. Although the near-surface channel conductance experiments reported herein were performed using (100)-oriented $\mathrm{Si}$ surfaces, the flatband potentials of (100)- and (111)-oriented $\mathrm{Si}$ surfaces are sufficiently similar $^{11}$ that the general conclusions derived from these measurements regarding the electrochemical potentials of the electrolyte solutions required to form an inversion layer are expected to be applicable, with only minor changes, to (111)oriented Si surfaces.

Differential capacitance $\left(C^{-2}\right)$ versus potential $(E)$ data were also collected to confirm independently the formation of an inversion layer for (111)-oriented Si surfaces in contact with the electrolyte solutions of interest (Table II). The slopes of plots of $C^{-2}$ vs $E$ yielded values in agreement with those calculated from the known dopant density of the sample and the calculated $C^{-2}$ values at each potential were independent of frequency, with a phase angle of $>87^{\circ}$, over the frequency range 5-100 kHz. The barrier heights calculated from the $x$ intercepts of such $C^{-2}$ vs $E$ plots for all of the (111)-oriented $n$-Si/liquid contacts clearly confirmed that an inversion layer had been formed as a result of charge transfer equilibration between the $\mathrm{Si}$ and the $\mathrm{I}_{2} / \mathrm{I}^{-}$and $\mathrm{Fc}^{+/ 0}$ systems in either THF or $\mathrm{CH}_{3} \mathrm{OH}$. Higher concentrations of redox-active reagents were required in these experiments to insure negligible concentration polarization in the $C^{-2}$ vs $E$ experiments, but low effective $S$ values were also measured under these conditions for contacts that formed inversion layers at the $n$-Si surface (Table II).

From the steady-state Shockley-Read-Hall (SRH) treatment, the surface recombination rate $U_{\mathrm{s}}$ for a surface with traps at a single midgap energy is a function of the surface electron- and hole-capture rate constants, $k_{\mathrm{n}, \mathrm{s}}$ and $k_{\mathrm{p}, \mathrm{s}}$, respectively, the electron and hole concentrations at the surface of the semiconductor in the dark, $n_{\text {so }}$ and $p_{\text {so }}$, respectively, and the injected electron and hole densities, $\Delta n_{\mathrm{s}}$ and $\Delta p_{\mathrm{s}}$, respectively:

$$
U_{s}=N_{T, s} \frac{k_{n, s} k_{p, s}\left(n_{s o} \Delta p_{s}+p_{s o} \Delta n_{s}+\Delta n_{s} \Delta p_{s}\right)}{k_{n, s}\left(n_{s o}+\Delta n_{s}+n_{1, s}\right)+k_{p, s}\left(p_{s o}+\Delta p_{s}+p_{1, s}\right)} .
$$


In Eq. (1), $N_{T, s}$ is the surface trap density and $n_{1, s}$ and $p_{1, s}$ are the electron and hole concentrations, respectively, when the Fermi level is located at the energy of the surface trap. A generalized SRH model, including effects of band bending and/or carrier inversion at Si surfaces, has been described recently. ${ }^{4,12}$ According to this generalized SRH model, low effective $S$ values can either be produced by an inherently small value of the surface trapping velocity, or by a higher, and potentially variable, value of $N_{T, S}$ accompanied by a high value of $p_{\text {so }}$ (or $n_{s o}$ ) in the denominator of Eq. (1). ${ }^{4,13}$ The experiments described herein clearly indicate that the latter situation, as a result of inversion, is occurring at the $n-\mathrm{Si} / \mathrm{CH}_{3} \mathrm{OH}-\mathrm{Fc}^{+/ 0}, n-\mathrm{Si} / \mathrm{CH}_{3} \mathrm{OH}-\mathrm{I}_{2}, n-\mathrm{Si} / \mathrm{THF}-\mathrm{I}_{2}$, and $n-\mathrm{Si} / \mathrm{THF}-\mathrm{Fc}^{+/ 0}$ contacts.

This inversion effect accounts for the similar surface recombination velocity behavior observed for silicon samples in contact with these solutions, even though the surface chemistries are known to be quite different. Exposure of $\mathrm{Si}$ to solutions of $\mathrm{Fc}^{+/ 0}$ in alcohol produces Si-alkoxide bonds, ${ }^{1,2}$ whereas exposure to $\mathrm{CH}_{3} \mathrm{OH}-\mathrm{I}_{2}$ solutions produces partial alkoxylation and partial $\mathrm{Si}-\mathrm{I}$ bonding. ${ }^{1,2}$ In contrast, no significant $\mathrm{Si}$ alkoxylation is formed as a result of exposure of crystalline $\mathrm{Si}$ to THF- $\mathrm{Fc}^{+/ 0}$ solutions. ${ }^{2}$ The chemical differences between these surfaces are manifested by the differing $S$ values obtained for these systems only when in contact with $\mathrm{N}_{2(g)}$ or in contact with THF-1.0 $\mathrm{M} \mathrm{LiClO}_{4}$ - or $\mathrm{CH}_{3} \mathrm{OH}-1.0 \mathrm{M} \mathrm{LiClO}_{4}$ Such chemical differences do not significantly change the effective $S$ values measured in contact with the oxidizing electrolytes $\left(\mathrm{Fc}^{+/ 0}, \mathrm{Br}_{2}, \mathrm{I}_{2}\right)$ due to the inversion layer that is formed under such conditions. The results described herein also indicate that the $\mathrm{Si}$ surfaces studied in this work do not display low $S$ values in contact with $N_{2(g)}$ or in contact with room air. Such surfaces will therefore have limited use for passivation of Si-based electrical devices. This stands in contrast to the passivation of $\mathrm{Si}$ through formation of surficial Si-alkyl bonding, which has recently been demonstrated to produce persistent, low $S$ values in contact with either $N_{2(g)}$ or air. ${ }^{14}$
In summary, near-surface channel conductance measurements and differential capacitance versus potential measurements have provided direct evidence for the formation of an inversion layer in $n$-type $\mathrm{Si}$ surfaces in contact with a variety of electrolytes of interest. This behavior is consistent with the known energetics of Si/liquid contacts, ${ }^{9}$ and explains the low effective surface recombination velocity values measured for these $n$-type Si/liquid contacts using photoconductivity charge carrier decay methods. ${ }^{1-7}$ Removal of the $n$-type $\mathrm{Si}$ surfaces from these electrolyte solutions eliminates the inversion layer, increases the effective surface recombination velocity to values in excess of $1 \times 10^{3} \mathrm{~cm} \mathrm{~s}^{-1}$, and produces values of $S$ that are different for all of these chemically different surfaces. ${ }^{3,4}$

The authors acknowledge the National Science Foundation, Grant No. CHE-9974562, for support of this work.

${ }^{1}$ J. A. Haber, I. Lauermann, D. Michalak, T. P. Vaid, and N. S. Lewis, J. Phys. Chem. B 104, 9947 (2000).

${ }^{2}$ J. A. Haber, and N. S. Lewis, J. Phys. Chem. (in press).

${ }^{3}$ W. J. Royea, D. J. Michalak, and N. S. Lewis, Appl. Phys. Lett. 77, 2566 (2000).

${ }^{4}$ F. Gstrein, D. Michalak, W. J. Royea, and N. S. Lewis, J. Phys. Chem. B 106, 2950 (2002)

${ }^{5}$ H. Msaad, J. Michel, J. J. Lappe, and L. C. Kimerling, J. Electron. Mater. 23, 487 (1994).

${ }^{6}$ H. Msaad, J. Michel, A. J. Reddy, and L. C. Kimerling, J. Electrochem. Soc. 142, 2833 (1995).

${ }^{7}$ T. S. Horanyi, T. Pavelka, and P. Tutto, Appl. Surf. Sci. 63, 306 (1993).

${ }^{8}$ P. E. Laibinis, C. E. Stanton, and N. S. Lewis, J. Phys. Chem. 98, 8765 (1994).

${ }^{9}$ M. L. Rosenbluth and N. S. Lewis, J. Am. Chem. Soc. 108, 4689 (1986).

${ }^{10}$ M. J. Weaver, in Comprehensive Chemical Kinetics, edited by R. G. Compton (Elsevier, New York, 1987), Vol. 27, p. 1.

${ }^{11}$ K. E. Pomykal, A. M. Fajardo, and N. S. Lewis, J. Phys. Chem. 100, 3652 (1996).

${ }^{12}$ A. G. Aberle, S. Glunz, and W. Warta, J. Appl. Phys. 71, 4422 (1992).

${ }^{13}$ W. Shockley and W. T. Read, Phys. Rev. 87, 835 (1952).

${ }^{14}$ W. J. Royea, A. Juang, and N. S. Lewis, Appl. Phys. Lett. 77, 1988 (2000). 